\title{
Anophthalmos, Microphthalmos, and Typical Coloboma in the United Kingdom: A Prospective Study of Incidence and Risk
}

\author{
Shabeen P. Shab, ${ }^{1,2}$ Amy E. Taylor, ${ }^{1}$ Jane C. Sowden, ${ }^{3,4}$ Nicola K. Ragge, ${ }^{5,6,7}$ \\ Isabelle Russell-Eggitt, ${ }^{3}$ Jugnoo S. Rabi, ${ }^{2,3}$ and Clare E. Gilbert, ${ }^{1}$ for the Surveillance of Eye \\ Anomalies (SEA-UK) Special Interest Group ${ }^{8}$
}

Purpose. Anophthalmos, microphthalmos, and typical coloboma (AMC) form an interrelated spectrum of congenital eye anomalies that can cause significant visual loss and cosmetic disfigurement in children. This prospective study of children born in the United Kingdom was undertaken to determine the incidence of AMC diagnosed by ophthalmologists and to explore sociodemographic risks.

MethoDs. Recruitment was achieved though an established active surveillance system of U.K. ophthalmologists supported by a new research network of interested specialists, the Surveillance of Eye Anomalies (SEA-UK) Special Interest Group. It started October 1, 2006, and continued over 18 months.

From the ${ }^{1}$ International Centre for Eye Health, London School of Hygiene and Tropical Medicine, London, United Kingdom; the ${ }^{2}$ MRC (Medical Research Council) Centre of Epidemiology for Child Health and the ${ }^{4}$ Developmental Biology Unit, Institute of Child Health, UCL (University College London), London, United Kingdom; the ${ }^{3}$ Ulverscroft Vision Research Group, Institute of Child Health and Great Ormond Street Hospital for Children, National Health Service (NHS) Trust, London, United Kingdom; ${ }^{5}$ Moorfields Eye Hospital, London, United Kingdom; the ${ }^{6}$ Department of Physiology, Anatomy, and Genetics, University of Oxford, Oxford, United Kingdom; and the ${ }^{7} \mathrm{Bir}-$ mingham Children's Hospital NHS Foundation Trust, Birmingham, United Kingdom.

${ }^{8}$ The study investigators are listed in the Appendix.

Supported by a grant from the Newlife Foundation. The funding source had no role in study design, data collection, data analysis, data interpretation, or in the writing of this paper. JSR, JCS and IR-E are members of the Ulverscroft Vision Research Group and are based at Great Ormond Street Hospital/UCL Institute of Child Health, which receives a proportion of its funding from the Department of Health's National Institute of Health Research (NIHR) Biomedical Research Centres funding scheme. JSR is based in the Medical Research Council's Centre of Epidemiology for Child Health and holds a joint appointment with Moorfields Eye Hospital/Institute of Ophthalmology, UCL, which also received a proportion of its funding from the NIHR Biomedical Research Centres funding scheme. NKR is a recipient of an Academy of Medical Sciences/Health Foundation Senior Surgical Scientist Award, and receives additional support from VICTA (Visually Impaired Children Taking Action), MACS (Microphthalmia, Anophthalmia, Children's Society), Polak Trust, and UK Comprehensive Loca Research Network (CLRN)

Submitted for publication January 25, 2010; revised April 6, 2010 accepted April 27, 2010.

Disclosure: S.P. Shah, None; A.E. Taylor, None; J.C. Sowden, None; N.K. Ragge, None; I. Russell-Eggitt, None; J.S. Rahi, None; C.E. Gilbert, None

Corresponding author: Shaheen P. Shah, International Centre for Eye Health, London School of Hygiene and Tropical Medicine, London WC1E 7HT, UK; shaheen.shah@Ishtm.ac.uk.
Results. One hundred thirty-five children were newly diagnosed with AMC. Typical colobomatous defects were the commonest phenotype, and anophthalmos was rare $(n=7)$. Both eyes were affected in $55.5 \%$ of the children. The cumulative incidence of AMC by age 16 years was 11.9 per 100,000 (95\% CI, 10.9-15.4). Of the children examined, $41.5 \%$ had not seen an ophthalmologist by 3 months of age. The incidence in Scotland was nearly double that in England and Wales. The children of Pakistani ethnicity had a 3.7 (95\% CI, 1.9-7.5) times higher risk of AMC than did white children. There was some evidence to suggest a higher incidence in the more socioeconomically deprived. The sibling risk ratio was 210 (95\% CI, 25-722).

Conclusions. This is the first prospective study of AMC, and it establishes the frequency across the United Kingdom. Comparisons with data quoted in the literature are difficult because study methodologies differ, but the frequency appears to be lower than that quoted for other developed countries. There are geographic and ethnic variations in incidence that warrant further investigation. (Invest Opbthalmol Vis Sci. 2011;52: 558-564) DOI:10.1167/iovs.10-5263

C ongenital anomalies are a significant cause of stillbirth, infant mortality, and disability worldwide. ${ }^{1}$ Clinical, epidemiologic, embryologic, and experimental evidence indicate that anophthalmos, microphthalmos, and typical coloboma (AMC) are an interrelated group of congenital ocular anomalies that are likely to have some genetic basis. ${ }^{2-7}$ These structural abnormalities are classified as major congenital anomalies, as they result in significant disability, ${ }^{8}$ and it is estimated that they are responsible for approximately $15 \%$ to $20 \%$ of blindness and severe visual impairment in children worldwide., ${ }^{7,9}$

The epidemiologic investigation of AMC is difficult for several reasons, and most published data are derived from national congenital anomaly registers. ${ }^{5,10-20}$ The population-based data on the frequency of typical coloboma are sparse, as most registries use the World Health Organization's International Classification of Diseases (ICD-10), ${ }^{21}$ in which the condition is not adequately classified. From the (mainly Western) literature, the birth prevalence of anophthalmos ranges from 0.6 to 4.2 per 100,000 births $^{5,10,15-16,20,22}$; from 2 to 17 per 100,000 births for microphthalmos $5,10,11,16,20,23$; and from 2 to 14 per 100,000 births for coloboma (predominantly of the iris). ${ }^{10,15,23-25}$ This wide range of reported frequencies should probably not be interpreted as a variation in risk between different populations as registers have important differences. For example, variability of diagnostic capabilities and diagnostic precision of different health systems (particularly for anomalies that require specialist examinations) and variability in completeness of case ascertainment ${ }^{26}$ are two factors that 
compromise comparisons between data derived from national anomaly registers.

Early detection of congenital eye anomalies is important for several reasons: Parents value early diagnosis, treatment and rehabilitation strategies may be more effective, and genetic counseling can be provided, if appropriate. ${ }^{6}$ The newborn and young infant vision-screening program recommends that all infants born in the United Kingdom be examined at birth and again at 6 to 8 weeks for ocular anomalies. Furthermore, it is recommended that all children in whom there is a family history of ocular anomaly be examined by an ophthalmologist within this period. ${ }^{27,28}$

The principal purpose of this study was to estimate the incidence of AMC (of any severity) diagnosed by ophthalmologists in children aged $<16$ years who were born in the United Kingdom. Secondary goals included determining sociodemographic variation and familial recurrence, as well as describing the age at which the diagnosis by the ophthalmologist was made. Findings of the etiologic investigations will be reported separately.

\section{Methods}

Children with AMC newly diagnosed by a National Health Service consultant ophthalmologist in the United Kingdom (England, Wales, Scotland, and Northern Ireland) were identified through the British Ophthalmic Surveillance Unit (BOSU), which manages an active surveillance scheme. ${ }^{29}$ All consultant ophthalmologists and those with clinical autonomy in the United Kingdom $(n=1131)$ (Foot B, BOSU coordinator, personal communication, 2006) were actively surveyed for 18 months between October 1, 2006, and March 31, 2008. They either noted that they had seen an eligible new case during the previous month or confirmed that they had no new cases to notify. ${ }^{29}$ In addition to this active surveillance process, a Special Interest Group (SIG) was formed to augment case reporting. The SIG consisted of 44 pediatric ophthalmologists with specialist training and interest in pediatric ophthalmology, as well as geneticists with an interest in AMC. It was anticipated that most children with AMC would be referred to these specialists.

A standardized questionnaire was sent to all ophthalmologists who had notified an eligible child to collect information that included identifiers to determine duplicate reports (i.e., date of birth, postal code, sex, and initials), sociodemographic data, and clinical information (see Supplementary Material, http://www.iovs.org/lookup/suppl/ doi:10.1167/iovs.10-5263/-/DCSupplemental). The questionnaire was piloted by SIG members before the start of the study. At least three reminders (two postal, one telephone) were sent to nonresponding ophthalmologists in an attempt to limit nonresponse.

\section{Case Definition of AMC}

As no formal classification has been developed for these anomalies, defining them for this study was complex. Clarification of the case definition, including inclusion and exclusion criteria, was sought from the BOSU Steering Committee and members of the SIG, to arrive at a consensus of opinion. For this clinical study anophthalmos was defined as no evidence of a globe or ocular tissue on clinical examination, since birth. Microphthalmos was defined as an abnormally small eye or cornea (microcornea): axial length, $<16 \mathrm{~mm}$ at birth, and $<19 \mathrm{~mm}$ at 12 months of age; and corneal diameter, $<10 \mathrm{~mm}$ at birth. As not all children would undergo measurement of ocular dimensions, the reference ranges were provided as a guide, but not as a diagnosing criterion. Differentiation of anophthalmos from severe microphthalmos was left to the reporting clinician. Coloboma was defined as a defect in any ocular tissue(s) consistent with failure of closure of the fetal fissure. To clarify the definition for clinicians, the following diagnoses were explicitly excluded: eyelid coloboma, anterior segment anomalies (e.g., aniridia, Peters' anomaly), and other posterior non- colobomatous anomalies (e.g., retinopathy of prematurity, persistent hyperplastic primary vitreous, and optic nerve hypoplasia).

\section{Data Management}

Data were double entered into a database (Access; Microsoft, Redmond, WA), and analysis was conducted (Stata; StatCorp., ver. 10.0, College Station, TX).

For analyses the following three mutually exclusive phenotypic categories were used at the level of the child: (1) any anophthalmos: unilateral or bilateral anophthalmos, irrespective of any other AMC anomaly in either eye; (2) isolated coloboma: unilateral or bilateral coloboma and no other AMC anomaly in either eye; (3) microphthalmos with or without coloboma: subdivided into (3a) isolated microphthalmos: unilateral or bilateral microphthalmos and no other AMC anomaly in either eye, and (3b) mixed: unilateral or bilateral microphthalmos and any other AMC defect in one or both eyes (includes microphthalmos + coloboma and microphthalmos with cyst).

Two other, non-mutually exclusive, phenotypic groups were also characterized: (1) any coloboma, which was defined as a child with any form of coloboma regardless of the presence of anophthalmos or microphthalmos; and (2) anophthalmos/microphthalmos (A/M), which was defined as unilateral or bilateral anophthalmos or microphthalmos, regardless of the presence of coloboma.

\section{Statistical Analysis}

There were approximately 1,158,000 live births during the study period. ${ }^{30}$ When possible, data were stratified by age, sex, ethnicity (according to the U.K. Office for National Statistics [ONS] classification; data available for Great Britain onl $y^{31}$ ), and England Government Office Regions (GORs). Place of residence was determined by using the postal code at the time of reporting, or the mother's postal code during pregnancy, if different. Socioeconomic status was determined by using the Index of Multiple Deprivation (IMD) for children born in England only (as this classification is country specific, and ranking from different countries cannot be usefully combined ${ }^{32,33}$ ). IMD rank was categorized into quintiles for analysis. Three categories of place of residence were determined (using postal code) for children born in England (as classification is country specific); urban, small town/fringe, and village/dispersed according to ONS-recommended classification.

In this study, incidence estimates were calculated in different ways. First, live birth, annual age-specific incidence of diagnosis of AMC by a U.K. ophthalmologist was estimated. The incidence of diagnoses of AMC in the first year of life was determined by dividing the number of newly diagnosed cases of AMC presenting in the first year of life by the annual number of live births in 2007 (denominator multiplied by 1.5 to account for 18-month study period). Second, the live birth risk (cumulative incidence) was calculated. Finally, the total annual incidence was calculated with the whole (living) population of children aged 0 to 15 years as the denominator. The advantage of the latter approach is that data could be analyzed by ethnic group, level of deprivation, and location of residence as population level data are available for these variables. To assess whether children born as singletons had the same incidence as those born as multiples, information on the number of live multiple births in England and Wales was obtained from the ONS. ${ }^{34}$ Risk ratios (RRs) were calculated using the method described by Clayton and Hills, ${ }^{35}$ and $95 \%$ confidence intervals (CIs) were based on the Poisson distribution.

Time from birth to diagnosis by an ophthalmologist was displayed as a survival function, and differences between phenotypes were tested by using the log rank test. ${ }^{36}$ Sibling risk $\left(K_{\mathrm{s}}\right)$ and sibling risk ratios $\left(\lambda_{\mathrm{s}}\right)$ were calculated as measures of familial aggregation. Sibling risk was defined as the number of siblings with an AMC, excluding the index case divided by the total number of siblings, again excluding the index case. Sibling risk ratio was defined as a ratio of risk of disease manifestation, given that one's sibling is affected, compared with the prevalence in the general population. The sibling risk ratio $\left(\lambda_{\mathrm{s}}\right)$ was 
calculated $\left(\lambda_{\mathrm{s}}=K_{\mathrm{s}} / K\right)$, where $K$ is the population risk of AMC, as determined from this study. ${ }^{37}$

The design and methodology of the study were reviewed and approved by the BOSU Steering Committee. The study was also approved by the Ethics Committee of the London School of Hygiene and Tropical Medicine (reference number 3091) and by the NHS London MREC (reference number 06/MREO2/45). The data were handled in accordance with current guidance on data protection. The research complied with the tenets of the Declaration of Helsinki.

\section{Results}

Eighty eligible cases were reported to BOSU, and 55 additional cases were reported through the SIG, making a total of 135 confirmed cases of AMC. Boys accounted for $50.4 \%$ of cases (Table 1). Isolated coloboma was the commonest phenotype

TABLE 1. The Demographic Distribution of AMC

\begin{tabular}{|c|c|c|c|c|}
\hline & \multicolumn{2}{|c|}{ Cases } & \multicolumn{2}{|c|}{ Child Population } \\
\hline & (n) & $\%$ & $(n)$ & $(\%)$ \\
\hline \multicolumn{5}{|l|}{ Country } \\
\hline England & 112 & 83.0 & $9,674,100$ & 84.0 \\
\hline Wales & 2 & 1.5 & 561,200 & 5.0 \\
\hline Scotland & 19 & 14.1 & 921,800 & 8.0 \\
\hline Northern Ireland & 2 & 1.5 & 380,100 & 3.0 \\
\hline UK Total & 135 & 100 & $11,537,200$ & 100 \\
\hline \multicolumn{5}{|l|}{ Sex } \\
\hline Male & 68 & 50.4 & $5,911,704$ & 51.0 \\
\hline UK total & 135 & 100 & $11,537,200$ & 100 \\
\hline \multicolumn{5}{|l|}{ Ethnicity* } \\
\hline White & 94 & 76.4 & $9,767,510$ & 87.9 \\
\hline Pakistani & 9 & 7.3 & 252,761 & 2.3 \\
\hline Mixed & 6 & 4.9 & 326,189 & 2.9 \\
\hline Bangladesh & 3 & 2.4 & 105,306 & 0.9 \\
\hline Indian & 3 & 2.4 & 233,594 & 2.1 \\
\hline African & 3 & 2.4 & 141,588 & 1.3 \\
\hline African Caribbean & 2 & 1.6 & 111,678 & 1.0 \\
\hline Other & 3 & 2.4 & 179,212 & 1.6 \\
\hline Great Britain total & $123^{*}$ & 100 & $11,117,837$ & 100 \\
\hline \multicolumn{5}{|l|}{ Deprivation England only† } \\
\hline Most deprived & 28 & 25.2 & $2,243,676$ & 23.1 \\
\hline Group 2 & 27 & 24.3 & $1,898,565$ & 19.5 \\
\hline Group 3 & 21 & 18.9 & $1,799,340$ & 18.5 \\
\hline Group 4 & 16 & 14.4 & $1,815,717$ & 18.7 \\
\hline Least deprived & 19 & 17.1 & $1,955,088$ & 20.1 \\
\hline England total & 111 & 100 & $9,712,386$ & 100 \\
\hline \multicolumn{5}{|l|}{$\begin{array}{l}\text { Dwelling location England } \\
\text { onlyt }\end{array}$} \\
\hline Urban & 91 & 82 & $7,931,478$ & 81.7 \\
\hline Small town and fringe & 9 & 8.1 & 907,824 & 9.3 \\
\hline Village and dispersed & 11 & 9.9 & 873,084 & 9.0 \\
\hline England total & 111 & 100 & $9,712,386$ & 100 \\
\hline \multicolumn{5}{|l|}{ GOR England only $\ddagger$} \\
\hline North East & 5 & 4.4 & 469,400 & 5.0 \\
\hline North West & 10 & 8.8 & $1,322,100$ & 14.0 \\
\hline Yorkshire/The Humber & 11 & 9.7 & 979,200 & 10.0 \\
\hline East Midlands & 5 & 4.4 & 819,500 & 8.0 \\
\hline West Midlands & 5 & 4.4 & $1,057,600$ & 11.0 \\
\hline East & 11 & 9.7 & $1,077,800$ & 11.0 \\
\hline London & 31 & 27.4 & $1,445,000$ & 15.0 \\
\hline South East & 23 & 20.4 & $1,581,400$ & 16.0 \\
\hline South West & 11 & 9.7 & 922,100 & 10.0 \\
\hline England total & 112 & 100 & $9,674,100$ & 100 \\
\hline
\end{tabular}

Ref, reference.

* 10 values missing.

† Requires postcode ( 1 missing value).

‡ Government Office Region (for England only), deprivation measured by Index of Multiple Deprivation.
TAble 2. Live Birth Risk (Cumulative Incidence) in the United Kingdom, by Phenotype

\begin{tabular}{|c|c|c|c|}
\hline $\begin{array}{c}\text { Disease State/Age at } \\
\text { Onset }\end{array}$ & $\boldsymbol{n}$ & $\begin{array}{l}\text { Incidence } \\
\text { per } 100,000\end{array}$ & $95 \% \mathrm{CI}$ \\
\hline \multicolumn{4}{|l|}{ AMC } \\
\hline By 1 Year & 119 & 10.4 & $8.6-12.4$ \\
\hline By 5 Years & 133 & 11.5 & $10.3-14.6$ \\
\hline By 16 Years & 135 & 11.9 & $10.9-15.4$ \\
\hline \multicolumn{4}{|l|}{ Any anophthalmos } \\
\hline By 1 year & 7 & 0.6 & $0.3-1.3$ \\
\hline \multicolumn{4}{|l|}{ Isolated coloboma } \\
\hline By 1 year & 49 & 4.3 & $3.1-5.6$ \\
\hline By 5 years & 58 & 5.1 & $4.1-7.0$ \\
\hline By 16 years & 62 & 5.5 & $4.5-7.6$ \\
\hline \multicolumn{4}{|l|}{ Isolated microphthalmos } \\
\hline By 1 year & 29 & 2.5 & $1.7-3.6$ \\
\hline By 5 years & 31 & 2.7 & $2.0-4.1$ \\
\hline \multicolumn{4}{|l|}{ Mixed } \\
\hline By 1 year & 34 & 3.0 & $2.1-4.2$ \\
\hline By 5 years & 35 & 3.1 & $2.3-4.5$ \\
\hline \multicolumn{4}{|l|}{$\mathrm{A} / \mathrm{M}^{*}$} \\
\hline By 1 year & 70 & 6.1 & $4.8-7.7$ \\
\hline By 5 years & 73 & 6.4 & $5.3-8.5$ \\
\hline \multicolumn{4}{|l|}{ Any coloboma $\dagger$} \\
\hline By 1 year & 85 & 7.4 & $5.9-9.2$ \\
\hline By 5 years & 95 & 8.4 & $7.1-10.8$ \\
\hline By 16 years & 99 & 8.7 & $7.5-11.5$ \\
\hline
\end{tabular}

* Anophthalmos/microphthalmos (i.e. regardless of presence of coloboma).

† Regardless of the presence of anophthalmos or microphthalmos.

( $n=62,45.9 \%$ ). Microphthalmos was present in 66 children: isolated in 31 (23\%) and mixed in 35 (25.9\%). Anophthalmos was rare, being present in only seven (5.2\%) children. In nearly three fourths of the children $(n=99,73.3 \%)$, a colobomatous defect was present (i.e., any coloboma). A/M was present in 73 (54.1\%) children.

The live birth incidence of AMC in the first year of life was 10.4 per 100,000 live births (95\% CI, 8.6-12.4; Table 2). This increased slightly with age, so that by the age of 16 years, the cumulative risk of an AMC anomaly in the United Kingdom was 11.9 per 100,000 (95\% CI, 10.9-15.4). Scotland had nearly twice the cumulative incidence of AMC (22.2 per 100,000; 95\% CI, 14.2-36.7) as did England and Wales (11.4 per 100,000; 95\% CI, 10.3-15.0).

As shown in Table 3, the annual live birth incidence of AMC for the under 16 population in the UK was 0.8/100,000 (95\% CI, 0.7-0.9). Significant ethnicity differences were apparent. However, these associations may be confounded by socioeconomic status, as $90.5 \%$ of children in the least deprived category were white compared with $61.3 \%$ in the most deprived $(P=0.003)$. Two-thirds of the Pakistani children were in the bottom two IMD categories compared to $36.8 \%$ of the white children. Furthermore, there was some evidence that the incidence was higher in the more deprived $(0.88 / 100,000$ per year (top two quintiles) vs. $0.62 / 100,000$ per year (bottom two quintiles), $P=0.04$ ).

The proportion of singletons in this study was lower than the national average $(95.8 \%$ vs. $98.5 \% ; P=0.03)$. The annual incidence of AMC in children aged less than 12 months and born as multiples was 32.9 per 100,000 (95\% CI, 10.8-76.8), which was higher than the incidence in singletons (RR 3.3; 95\% CI, 1.3-8.0; $P=0.006$ ).

Nine $(8.3 \%)$ sets of parents had consanguineous marriages with the following relationships: first cousins $(n=3)$, second cousins $(n=2)$, uncle/niece $(n=1)$ and unknown $(n=3)$. Half the couples were Pakistani. In 18 (13.3\%) children, there was a positive history of a congenital eye anomaly in another 
TABLE 3. Total Annual Live Birth Incidence ( $<16$ Years) of any AMC Anomaly

\begin{tabular}{|c|c|c|c|c|c|}
\hline & $\begin{array}{l}\text { Annual Live Birth } \\
\text { Incidence } / 100,000 / y\end{array}$ & $95 \% \mathrm{CI}$ & Relative Rate & $95 \% \mathrm{CI}$ & $\boldsymbol{P}$ \\
\hline Overall UK & 0.78 & $0.68-0.94$ & & & \\
\hline \multicolumn{6}{|l|}{ Country } \\
\hline England & 0.77 & $0.65-0.94$ & Ref & & \\
\hline Wales & 0.24 & $0.03-0.86$ & 0.31 & $0.07-1.22$ & 0.075 \\
\hline Scotland & 1.37 & $0.83-2.15$ & 1.78 & $1.08-2.84$ & 0.022 \\
\hline Northern Ireland & 0.35 & $0.04-1.30$ & 0.45 & $0.11-1.81$ & 0.245 \\
\hline \multicolumn{6}{|l|}{ Sex } \\
\hline Male & 0.77 & $0.62-0.99$ & Ref & & \\
\hline Female & 0.79 & $0.62-1.01$ & 1.02 & $0.72-1.43$ & 0.912 \\
\hline \multicolumn{6}{|l|}{ Ethnicity* } \\
\hline White & 0.64 & $0.51-0.77$ & Ref & & \\
\hline Pakistani & 2.37 & $1.09-4.51$ & 3.70 & $1.9-7.5$ & $<0.001$ \\
\hline Bangladesh & 1.90 & $0.70-6.50$ & 2.96 & $1.0-9.55$ & 0.047 \\
\hline Indian & 0.86 & $0.18-2.50$ & 1.33 & $0.67-4.94$ & 0.234 \\
\hline African & 1.41 & $0.11-3.40$ & 2.20 & $0.71-7.1$ & 0.155 \\
\hline African Caribbean & 1.19 & $1.31-7.80$ & 1.86 & $0.47-7.7$ & 0.36 \\
\hline Mixed & 1.23 & $0.13-1.80$ & 1.91 & $0.85-4.46$ & 0.105 \\
\hline Other & 1.12 & $0.23-3.30$ & 1.74 & $0.56-5.61$ & 0.32 \\
\hline \multicolumn{6}{|l|}{ Deprivation $\dagger$} \\
\hline Most deprived & 0.83 & $0.60-1.30$ & Ref & & \\
\hline Group 2 & 0.95 & $0.68-1.50$ & 1.14 & $0.68-1.91$ & 0.618 \\
\hline Group 3 & 0.78 & $0.48-1.20$ & 0.94 & $0.46-1.46$ & 0.493 \\
\hline Group 4 & 0.59 & $0.31-0.91$ & 0.71 & $0.29-1.06$ & 0.073 \\
\hline Least deprived & 0.65 & $0.36-0.97$ & 0.78 & $0.38-1.24$ & 0.208 \\
\hline \multicolumn{6}{|l|}{ Dwelling $\dagger$} \\
\hline Urban & 0.77 & $0.65-0.97$ & Ref & & \\
\hline Small town and fringe & 0.66 & $0.25-1.16$ & 0.85 & $0.36-1.51$ & 0.403 \\
\hline Village and dispersed & 0.84 & $0.37-1.40$ & 1.09 & $0.5-1.83$ & 0.893 \\
\hline \multicolumn{6}{|l|}{ GOR $\ddagger$} \\
\hline North East & 0.71 & $0.23-1.66$ & Ref & & \\
\hline North West & 0.50 & $0.24-0.93$ & 0.71 & $0.24-2.08$ & 0.529 \\
\hline Yorkshire/The Humber & 0.75 & $0.37-1.30$ & 1.05 & $0.37-3.04$ & 0.922 \\
\hline East Midlands & 0.41 & $0.13-0.95$ & 0.57 & $0.17-1.98$ & 0.372 \\
\hline West Midlands & 0.32 & $0.07-0.65$ & 0.44 & $0.1-1.32$ & 0.11 \\
\hline East & 0.68 & $0.34-1.22$ & 0.96 & $0.33-2.75$ & 0.937 \\
\hline London & 1.43 & $1.05-2.14$ & 2.01 & $0.83-5.49$ & 0.104 \\
\hline South East & 0.97 & $0.58-1.40$ & 1.37 & $0.5-3.45$ & 0.59 \\
\hline South West & 0.80 & $0.50-1.61$ & 1.12 & $0.47-3.71$ & 0.593 \\
\hline
\end{tabular}

Ref, reference.

* Ethnicity data (Great Britain only) unknown in 10 children.

† Derived from English postcode, unknown in one.

‡ English Government Office Regions.

family member, and in 11 this was another AMC abnormality. Sibling recurrence risk $\left(K_{\mathrm{s}}\right)$ was $2.5 \%$ (95\% CI, $\left.0.3 \%-8.6 \%\right)$. Using the population risk of AMC determined in this study the sibling risk ratio $\left(\lambda_{\mathrm{s}}\right)$ was calculated as 210 (95\% CI, 25-722). The mean age of a first-time mother was slightly older than the national average (28.8 years vs. 27.6 years, $P=0.26$ ).

In just over one third of cases, diagnosis was made by an ophthalmologist by 1 month of age $(n=52,38.5 \%)$ and $58.5 \%$ by 3 months of age. All children had received the diagnosis by the 10th birthday. Significant differences existed in diagnosis according to ocular phenotype, with isolated coloboma being diagnosed significantly later than more severe defects (Fig. 1). Among the children in whom isolated coloboma was diagnosed after 3 months $(n=35)$, visible iris coloboma was present in more than half (57.1\%).

In most cases (58.3\%), the eye abnormality was first identified by a family member. Hospital pediatricians were the first health professionals to notice the eye anomaly in $29.3 \%$ of children. Nine children had the abnormality detected in the community (the general practitioner, $n=3$; community optometrist, $n=4$; midwife, $n=1$; or health visitor, $n=1$ ).

Bilateral AMC was recorded in 75 (55.5\%) children, and the proportion did not vary by phenotype. Unilateral AMC was diagnosed significantly later than bilateral defects (diagnosed after 1 month in $73.3 \%$ of children with unilateral defects vs. $52 \%$ with bilateral defects, $P=0.01$ ). This disparity was even

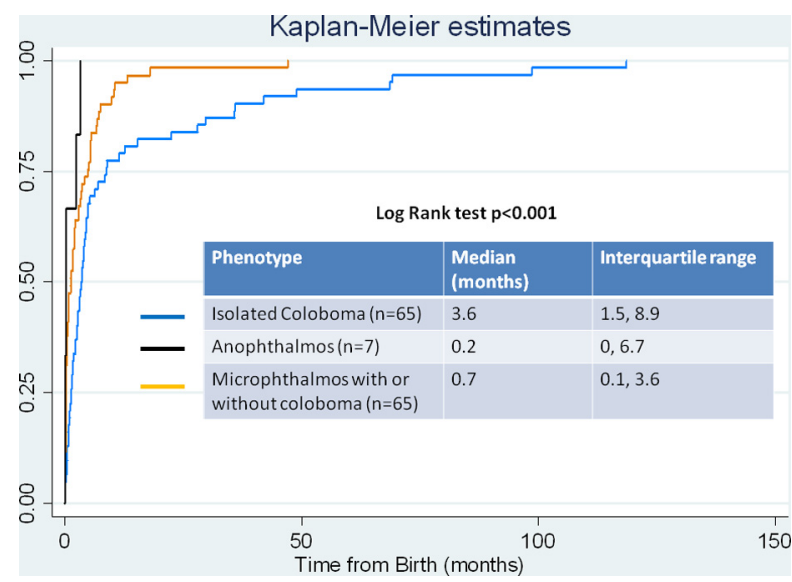

Figure 1. Time to diagnosis stratified by phenotype. 
more apparent by 3 months (diagnosed after 3 months in $61.7 \%$ of children with unilateral defects vs. $25.3 \%$ with bilateral defects, $P<0.001)$. AMC was diagnosed by 3 months of age in only three of the six children who had a first-degree relative with the disease.

\section{Discussion}

This is the first prospective study of incident AMC in the United Kingdom, and the cumulative risk by the age of 16 years was estimated at 1 case in every 8400 live births. The cumulative incidence appears to be lower than birth prevalences quoted for other regions; however, comparison with registry data was problematic. Most registers use passive surveillance data collection methods and can include misclassifications (particularly for anomalies that require specialist examinations). For example, 39\% of children registered with AMC in the Scottish National Congenital Anomalies register were subsequently found to have been misclassified. ${ }^{2}$ Comparison with other studies is also difficult due to variation in case definitions or inclusion and exclusion criteria. For example, most other studies have not included coloboma or, if they did, only iris coloboma was included. Some studies exclude chromosomal abnormalities, ${ }^{38}$ or unilateral or mild conditions, ${ }^{11}$ whereas other studies include still births and fetuses from terminated pregnancies. ${ }^{14,15}$ These differences are likely to have an effect not only on frequency estimates but also on the range and severity of the anomalies reported.

The study most comparable to ours, in which the diagnosis of AMC was also confirmed by eye specialists, was undertaken in Scotland between 1981 and 1997. In this study, the live birth prevalence was estimated to be 19 of 100,000 live births, ${ }^{2}$ which is similar to the frequency found in Scotland in the present study. Another study undertaken in England between 1988 and 1994 , retrospectively ascertained cases of anophthalmos and microphthalmos from multiple sources. ${ }^{38}$ In that study, the birth prevalence was estimated to be 10 per 100,000 live births (95\% CI, 9-11).

Our study found a higher risk of AMC in Scotland than in England, in line with findings that a higher proportion of children have visual impairment, due to whole-globe anomalies in Scotland compared with England. ${ }^{39,40}$ Congenital glaucoma has a greater frequency in Scotland ${ }^{41}$ than in the rest of the United Kingdom, and a north-south British divide has also been reported for several other congenital anomalies. ${ }^{42} \mathrm{Com}-$ pared with elsewhere in Europe, a higher prevalence of anomalies has been noted in Glasgow. ${ }^{43}$ Scotland has a reputation for poor health, termed the "Scottish effect," with markedly worse mortality and morbidity rates than the rest of Britain. ${ }^{44}$ Whether a Scottish effect is apparent in congenital anomaly rates is unclear, as there are other possible explanations for these findings. For example, case ascertainment may be more complete in Scotland than elsewhere in the United Kingdom and Europe. The lower rate of termination of pregnancy (12.4/ 1000 women aged 15 to 44 years in Scotland compared with 18.3 for the same age group in England and Wales, 2006) may also be a factor. ${ }^{45}$

Ethnic minorities (in particular children of Pakistani and Bangladeshi ethnicity) appear to have a higher incidence of AMC than do white children. This finding is consistent with data from other epidemiologic studies undertaken in south Asian countries, which are estimated to have the highest prevalence of severe visual loss from congenital ocular anomalies. In the United Kingdom, a significantly higher incidence of congenital glaucoma was also found in Pakistani children. ${ }^{41}$ Reasons for the increased risk are unclear, and both genetic and environmental influences are likely to be important. The practice of consanguineous marriage is particularly common in these ethnic groups, and parental consanguinity is high among children with AMC. ${ }^{15,46}$ Although consanguinity is known to increase the risk of autosomal recessive conditions, the adverse effect is often exaggerated, as many studies do not take into account the potential confounders, such as socioeconomic status and maternal education. There are also likely to be differences in attitude and behavior in relation to antenatal care and termination of pregnancy between groups that do or do not practice consanguineous marriage. ${ }^{47,48}$ Investigating socioeconomic inequalities can reveal etiologic clues, as was the case for nutritional deficiency and neural tube defects. ${ }^{49}$ Increasing socioeconomic deprivation has been identified as a risk factor for some anomalies, ${ }^{50}$ and the present study showed some evidence that the more deprived areas had a higher incidence of AMC than did the more affluent areas $(P=0.04)$. This finding is also relevant in the context of needs assessment and effective targeting of services. Differences in deprivation by ethnicity are observed in the U.K. population as a whole and were observed within our sample; but, unfortunately, as IMD data were not available stratified by ethnic group at the population level, it was not possible to adjust our risk estimates for confounding by socioeconomic status.

Children born in multiple births appeared to have a higher incidence of AMC than did singletons, which is consistent with other studies of eye/other anomalies. ${ }^{11,13,51}$ Greater maternal age and the use of assisted reproduction technology (ART) are both associated with multiple births, and if current trends for increasing maternal age and use of ART continue, the incidence of AMC may also increase.

Diagnosis by 3 months of age has been suggested as a useful cutoff for evaluating the national newborn and young infants vision-screening program. ${ }^{52}$ Applying the 3-month cutoff to the data in our study meant that some children with visually obvious anomalies (e.g., iris coloboma) received a late diagnosis. Some children who would benefit from early intervention (e.g., those with microphthalmos and cataract) also received a late diagnosis. Such findings suggest that the newborn and young-infant vision screening program, which is not routinely monitored, may benefit from formal evaluation to determine coverage, quality, and best practice. Introducing a mandatory pupil-dilated examination, as has been introduced in some U.S. states, may be useful, as it is recognized that the more subtle anomalies (an isolated chorioretinal coloboma for example) may not be identified with the current screening method.

The aggregation of a disease within a family is often the first clue of underlying genetic susceptibility. In line with our findings, Morrison et al. ${ }^{2}$ estimated a sib recurrence risk $\left(K_{\mathrm{s}}\right)$ of $6 \%$ and a sib risk ratio $\left(\lambda_{\mathrm{s}}\right)$ of 316 in Scotland. These figures provide genetic counselors with information that may help parents in planning future pregnancies. The modest sibling risk of AMC, which is similar to other complex diseases (e.g., neural tube defects), ${ }^{53}$ reflects the role of genetic heterogeneity, the likely oligogenic effects, and the interaction with environmental factors in the etiology of AMC. Of importance, however, in view of emerging genetic identification of these syndromes, ${ }^{6}$ is the offer of a genetic diagnosis.

Isolated colobomata were found to be diagnosed later than more severe anomalies in this study, which is relevant, as it has a bearing on the frequency estimate. In anomaly research, birth prevalence is a commonly quoted measure of disease frequency, but its reliability is dependent on the upper age limit for registration, meaning that milder anomalies, which are detected when the child is older, are more likely to be underascertained. Upper age limits for registration vary between registers. For example, the Alberta Congenital Anomalies Surveillance System ${ }^{12}$ eligibility criteria specify that the child must be under the age of 1 year to qualify for registration but, in the 
Spanish collaborative study, ${ }^{5}$ the notification period was the first 3 days of life. This latter study reported a birth prevalence of anophthalmos similar to that of coloboma, suggesting that coloboma was markedly underreported. Our study therefore quotes age-specific and cumulative incidence of diagnosis of AMC as measures of disease frequency. In addition, such estimates provide insight into the diagnosing and notifying process of the health care system.

Completeness of ascertainment is always a concern in any epidemiologic study of rare disease. For this reason, we chose the method of active surveillance, as it yields a high ascertainment rate. ${ }^{54-57}$ The method also allows standardized data collection, thus reducing observer bias. ${ }^{58}$ In addition, the United Kingdom's National Health Service, which provides a universal cost-free service, is ideally suited for active surveillance. The unique BOSU system has a track record of supporting the study of rare pediatric ophthalmic disorders over the last 11 years. ${ }^{39,41,52,59}$ But despite this, as ascertainment is unlikely to be $100 \%$, the data quoted in our study are likely to be minimum estimates. The BOSU card return rate by ophthalmologists during the study period was $77 \%$ (Foot B, BOSU co-ordinator; personal communication, 2006), and return rates can vary by reporting region, allowing the possibility of differential case reporting. A further concern was that $13 \%$ of notifying ophthalmologists could not remember the child's details and therefore could not complete the questionnaire. This problem has been recognized in other BOSU studies. In our study, the successful development and use of a geographically widespread SIG as a safety net for case ascertainment has limited these concerns. The study requirement that every child be examined by an experienced ophthalmologist meant that the ocular phenotype was as accurate as possible, but it also meant that children born with life-threatening systemic anomalies who died before being seen by an ophthalmologist would be missed. As the study did not require ocular examination of siblings, underreporting of eye anomalies in siblings would lead to an underestimate of familial risk. It is also important to remember that associations between deprivation and AMC may be subject to the ecological fallacy (i.e., postal code data may not imply individual exposure). Several children reported to the study were not eligible for inclusion, as they did not fit the case definition. We recognize that the continued lack of international standardization of terminology ${ }^{60}$ should be addressed.

In summary, accurate epidemiologic studies are an important step toward quantifying the public health importance of conditions and are necessary for planning eye care services for the children and their families, as well as for investigating secular trends and/or clustering. This study provides, for the first time, minimum incidence estimates of confirmed AMC for the United Kingdom. The methods used in this study were different from those used in earlier studies of AMC, but we believe the results to be applicable to other populations of similar composition. South Asian children appeared to be at higher risk and a U.K. cohort study of pregnant mothers, currently in recruitment in an area where almost half the infants born have parents of Pakistani origin, may reveal some of the complex interactions that affect health in these communities. ${ }^{61}$ The apparently higher incidence in Scotland and evidence of late identification (possibly due to inadequate screening of neonates) also requires further investigation. Last, this study demonstrates the feasibility of using a prospective study design for recruitment to a collaborative multicenter study of AMC.

\section{References}

1. Petrini J, Damus K, Russell R, Poschman K, Davidoff MJ, Mattison D. Contribution of birth defects to infant mortality in the United States. Teratology. 2002;66(suppl 1):S3-S6.
2. Morrison D, FitzPatrick D, Hanson I, et al. National study of microphthalmia, anophthalmia, and coloboma (MAC) in Scotland: investigation of genetic aetiology. J Med Genet. 2002;39(1):16-22.

3. Gregory-Evans CY, Williams MJ, Halford S, Gregory-Evans K. Ocular coloboma: a reassessment in the age of molecular neuroscience. J Med Genet. 2004;41(12):881-891.

4. Verma A, FitzPatrick D. Anophthalmia and microphthalmia. Orphanet J Rare Dis. 2007;2(1):47.

5. Bermejo E, Martinez-Frias ML. Congenital eye malformations: clinical-epidemiological analysis of 1,124,654 consecutive births in Spain. Am J Med Genet. 1998;75(5):497-504.

6. Ragge NK, Subak-Sharpe ID, Collin JR. A practical guide to the management of anophthalmia and microphthalmia. Eye. 2007; 21(10): $1290-1300$.

7. Hornby SJ, Gilbert CE, Rahi JK, et al. Regional variation in blindness in children due to microphthalmos, anophthalmos and coloboma. Ophthalmic Epidemiol. 2000;7(2):127-138.

8. Czeizel AE, Intôdy Z, Modell B. What proportion of congenital abnormalities can be prevented? BMJ. 1993;306:499-503.

9. Gilbert C, Foster A. Childhood blindness in the context of VISION 2020: the right to sight. Bull World Health Organ. 2001;79(3): 227-232.

10. Clementi M, Tenconi $\mathrm{R}$, Bianchi $\mathrm{F}$, et al. Congenital eye malformations: a descriptive epidemiologic study in about one million newborns in Italy. Birth Defects Orig Artic Ser. 1996;30(1): 413-424.

11. Shaw GM, Carmichael SL, Yang W, Harris JA, Finnell RH, Lammer EJ. Epidemiologic characteristics of anophthalmia and bilateral microphthalmia among 2.5 million births in California, 1989-1997. Am J Med Genet A. 2005;137(1):36-40.

12. Lowry RB, Kohut R, Sibbald B, Rouleau J. Anophthalmia and microphthalmia in the Alberta Congenital Anomalies Surveillance System. Can J Ophthalmol. 2005;40(1):38-44.

13. Forrester MB, Merz RD. Descriptive epidemiology of anophthalmia and microphthalmia, Hawaii. 1986-2001 Birth Defects Res A Clin Mol Teratol. 2006;76(3):187-192.

14. EUROCAT. Annual Report to WHO 20045. http://www.eurocat.ulster. ac.uk/pdf/EUROCAT-Annual-Report-2005-for-WHO.pdf. Belfast: Northern Ireland: University of Ulster; 2005. Accessed 2008.

15. Stoll C, Alembik Y, Dott B, Roth MP. Congenital eye malformations in 212,479 consecutive births. Ann Genet. 1997;40(2):122-128.

16. Spagnolo A, Bianchi F, Calabro A, et al. Anophthalmia and benomyl in Italy: a multicenter study based on 940,615 newborns. Reprod Toxicol. 1994;8(5):397-403.

17. Stoll C, Alembik Y, Dott B, Roth MP. Epidemiology of congenital eye malformations in 131,760 consecutive births. Ophthalmic Paediatr Genet. 1992;13(3):179-186.

18. Vogt G, Puho E, Czeizel AE. A population-based case-control study of isolated anophthalmia and microphthalmia. Eur J Epidemiol. 2005;20(11):939-946.

19. Vogt G, Puho E, Czeizel AE. A population-based case-control study of isolated ocular coloboma. Ophthalmic Epidemiol. 2005;12(3): 191-197.

20. Kallen B, Tornqvist $\mathrm{K}$, The epidemiology of anophthalmia and microphthalmia in Sweden. Eur J Epidemiol. 2005;20(4):345-350.

21. World Health Organization. ICD-10 International Statistical Classification of Diseases and Related Health Problems. 10th Revision. Geneva: WHO; 1994.

22. International Clearinghouse for Birth Defects Surveillance and Research. Annual Report. Rome, Italy: ICBDSR; 2005.

23. Hu DN. Prevalence and mode of inheritance of major genetic eye diseases in China. J Med Genet. 1987;24(10):584-588.

24. Lu BX. An analysis of 193 cases of congenital intraocular colobomas (in Chinese). Zhonghua Yan Ke Za Zhi. 1989;25(6):357-359.

25. Vogt G, Szunyogh M, Czeizel AE. Birth characteristics of different ocular congenital abnormalities in Hungary. Ophthalmic Epidemiol. 2006;13(3):159-166.

26. Boyd PA, Armstrong B, Dolk H, et al. Congenital anomaly surveillance in England: ascertainment deficiencies in the national system. BMJ. 2005;330(7481):27. 
27. Elliman DA, Dezateux C, Bedford HE. Newborn and childhood screening programmes: criteria, evidence, and current policy. Arch Dis Child. 2002;87(1):6-9.

28. Hall DM. Report of the Third Joint Working Party on Child Health Surveillance. 3rd ed. 1996, Oxford, UK: Oxford University Press 1996.

29. Stanford, MR. A British ophthalmological surveillance unit. British Ophthalmological Surveillance Unit Steering Committee. Br J Oph thalmol. 1997;81(11):932-933.

30. Office of National Statistics. National Statistics Postal code Directory: User Guide. Available at http://geoconvert.mimas.ac.uk/help/ documentation/07feb/User\%20Guide/NSPD\%20User\%20Guide\% $202007 \% 20 v 1$.pdf. London: HMSO, Office of National Statistics 2007. Accessed 2008.

31. Office of National Statistics. Ethnic Group Statistics: A Guide for the Collection and Classification of Ethnicity Data. London: HMSO, Office of National Statistics; 2003.

32. Noble $\mathrm{M}$, Wright $\mathrm{G}$, Dibben $\mathrm{C}$, et al. The English Indices of Deprivation. London: Office of the Deputy Prime Minister; 2004.

33. Office of National Statistics. Indices of deprivation across the UK. Neigbbourbood Statisitics 2008. London: HMSO; 2009.

34. Office of National Statistics. Birth Statistics: Review of the Registrar General on Births and Patterns of Family Building in England and Wales. Newport, UK: HMSO; 2006.

35. Clayton D, Hills M. Statistical Models in Epidemiology. Oxford, UK: Oxford University Press; 1993.

36. Bland MJ. The logrank test. BMJ. 2004;328:1073.

37. Carter N, Williamson L, Kennedy LG, Brown MA, Wordsworth BP. Susceptibility to ankylosing spondylitis. Rbeumatology (Oxford). 2000;39(4):445.

38. Dolk H, Busby A, Armstrong BG, Walls PH. Geographical variation in anophthalmia and microphthalmia in England. 1988-94. BMJ. 1998;317(7163):905-909, discussion 910.

39. Rahi JS, Cable N. Severe visual impairment and blindness in children in the UK. Lancet. 2003;362(9393):1359-1365.

40. Blaikie AJ, Ravenscroft J, Buultjens M, Dutton GN. Development of an Inclusive Childbood Visual Impairment Notification System. Presented at the Royal College of Ophthalmologists Congress 2003, Birmingham, UK.

41. Papadopoulos M, Cable N, Rahi J, Khaw PT. The British Infantile and Childhood Glaucoma (BIG) Eye Study. Invest Ophthalmol Vis Sci. 2007;48(9):4100-4106.

42. Rankin J, Pattenden S, Abramsky L, et al. Prevalence of congenita anomalies in five British regions, 1991-99. Arch Dis Child Fetal Neonatal Ed. 2005;90(5):F374-F379.

43. Dastgiri $\mathrm{S}$, et al. Prevalence and secular trend of congenital anomalies in Glasgow, UK. Arch Dis Child. 2002;86(4):257-263.

44. Sridharan S, Tunstall H, Lawder R, Mitchell R. An exploratory spatial data analysis approach to understanding the relationship between deprivation and mortality in Scotland. Soc Sci Med. 2007; 65(9):1942-1952.

45. Information Services Division Scotland. Statistical Publication Notice, Abortion Statistics, Year Ending December 2006. Glasgow: NHS National Services Scotland; 2007. Available at http://www. isdscotland.org/isd/4871.html.

46. Porges Y, et al. Hereditary microphthalmia with colobomatous cyst. Am J Opbthalmol. 1992;114(1):30-34.

47. Lumb KM, Congdon PJ, Lealman GT. A comparative review of Asian and British-born maternity patients in Bradford. 1974-8. J Epidemiol Community Health. 1981;35(2):106-109.

48. Bennett RL, Hudgins L, Smith Co, Motulsky AG. Inconsistencies in genetic counseling and screening for consanguineous couples and their offspring: the need for practice guidelines. Genet Med. 1999; 1(6):286-292.

49. Little J, Elwood H, eds. Socio-economic Status and Occupation. Epidemiology and Control of Neural Tube Defects. Oxford, UK Oxford University Press; 1992.

50. Vrijheid M, Dolk H, Stone D, Abramsky L, Alberman E, Scott JE. Socioeconomic inequalities in risk of congenital anomaly. Arch Dis Child. 2000;82(5):349-352.
51. Glinianaia SV, Rankin J, Wright C. Congenital anomalies in twins: a register-based study. Hum Reprod. 2008;23(6):1306-1311.

52. Rahi JS, Dezateux C. National cross sectional study of detection of congenital and infantile cataract in the United Kingdom: role of childhood screening and surveillance; the British Congenital Cataract Interest Group. BMJ. 1999;318(7180):362-365.

53. McDonnell RJ, et al. East Ireland 1980-1994: epidemiology of neural tube defects. J Epidemiol Community Health. 1999;53(12): $782-788$.

54. Thacker SB, Redmond S, Rothenberg RB, Spitz SB, Choi K, White MC. A controlled trial of disease surveillance strategies. Am J Prev Med. 1986;2(6):345-350.

55. Farrington P, Pugh S, Colville A, et al. A new method for active surveillance of adverse events from diphtheria/tetanus/pertussis and measles/mumps/rubella vaccines. Lancet. 1995;345(8949): 567-569.

56. Vogt RL, LaRue D, Klaucke DN, Jillson DA. Comparison of an active and passive surveillance system of primary care providers for hepatitis, measles, rubella, and salmonellosis in Vermont. Am J Public Health. 1983;73(7):795-797.

57. Hobbs CA, Hopkins SE, Simmons CJ. Sources of variability in birth defects prevalence rates. Teratology. 2001;64(suppl 1):S8-S13

58. Elliott EJ, Chant KG, Rare disease surveillance. J Paediatr Child Health. 1994;30(6):463-465.

59. Stanford MR, Tan HK, Gilbert RE. Toxoplasmic retinochoroiditis presenting in childhood: clinical findings in a UK survey. $\mathrm{BrJ}$ Opbthalmol. 2006;90(12):1464-1467.

60. Warburg M. Small eyes: descriptional misconceptions. Am J Med Genet. 1995;59(3):388-389.

61. http://www.borninbradford.nhs.uk. Accessed 2008.

\section{Appendix}

\section{Members of the SEA-UK Special Interest Group, United Kingdom}

Addenbrooke's Hospital, Cambridge: Louise Allen; Birmingham Children's Hospital, Birmingham: John Ross Ainsworth; Bristol Eye Hospital, Bristol: Amanda Churchill, Richard Markham, Cathy Williams; Optometry and Visual Science Service, City University, London: Alistair Fielder; Great Ormond Street Hospital, London: Yassir Abbou-Rayyah, Ken Nischal; Guy's and St. Thomas' Hospital, London: Louis Amaya; Hinchingbrooke Hospital, Huntingdon: Melanie Hingorani; King's College Hospital, London: Wagih Aclimandos; Leicester Royal Infirmary, Leicester: Samira Anwar, Geoff Woodruff; Moorfields Eye Hospital, London: Yassir Abbou-Rayyah, Gill Adams, Richard Collin, Tony Moore, Alison Salt, John Sloper; MRC Human Genetics Unit, Edinburgb: David Fitzpatrick, Veronica van Heyningen; Ninewells Hospital, Dundee: Nicolas George; Oxford Eye Hospital, Oxford: John Elston; Princess Alexandra Eye Pavilion, Edinburgb: Brian Fleck, Alan Mulvihill; Queen's Medical Centre, Nottingham: Richard Gregson, John Stokes; Royal Devon and Exeter Hospital, Exeter: Anthony Quinn; Royal Eye Hospital, Manchester: Chris Lloyd; Royal Hospital for Sick Children, Glasgow: Gordon Dutton; Royal Liverpool Children's Hospital, Liverpool: Sean Chen, William Newman; Royal London Hospital, London: Ashwin Reddy; Royal Victoria Infirmary, Newcastle: Mike Clarke; St. James's Hospital, Leeds: Vernon Long, Ian Simmons; St. Mary's Hospital, Manchester: Graeme Black; St. Thomas' Hospital, London: Danny Morrison; Sutton Hospital, Surrey: Jane Leitch; University Hospital of Wales, Cardiff: Patrick Watts; Opbthalmology Group, University of Leicester, Leicester: Irene Gottlob; West Suffolk Hospital, Suffolk: Anthony Vivian; York Hospital: York: Robert Taylor; and Yorkbill Hospital, Glasgow: Tim Lavy, Jane MacKinnon. 